\title{
FEATURE
}

\section{FFP3 respirator face fit testing - what is it all about?}

\section{By Laura Rollings}

\section{Abstract}

Coronavirus and the resultant pandemic have changed how dentists work. Dental professionals require a fit test to wear a certain type of personal protective equipment (PPE) - the filtering facepiece class 3 (FFP3) mask. We explain two types of fit tests: quantitative and qualitative, with step-by-step images demonstrating the latter. The four reasons for having a face fit test will be explained. This article will introduce and explain the fit check, which should be performed every time a FFP3 mask is worn.

\section{Introduction}

The new coronavirus was first discovered in Wuhan in December 2019. ${ }^{1}$ Its resultant disease was officially named COVID-19 (ie coronavirus disease 2019) by the World Health Organisation in February 2020. ${ }^{2}$ As a result of the current pandemic, personal protective equipment (PPE) is undoubtedly at the forefront of many dental professionals' thoughts. PPE requirements are detailed in the NHS's Standard Operating Procedure: Transition to Recovery publication, ${ }^{3}$ which should be adapted locally. Countless professionals have undergone or are awaiting a fit test for a filtering facepiece class 3 (FFP3) respirator. ${ }^{4}$ Like many, this will be a new concept. There are two tests available: quantitative and qualitative. ${ }^{5}$

What is a FFP3 mask and how much is filtered by it?

A FFP3 respirator, ${ }^{4}$ also referred to as a FFP3 mask, ${ }^{6}$ is a type of PPE. There are different types, sizes and models of FFP3 masks. ${ }^{6}$ FFP3 masks include the $3 \mathrm{M} 8833^{7}$ (Fig.

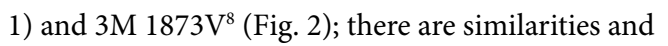
differences between them. At the anterior aspect of the mask, they both have a central valve; this design allows heat to escape and reduces eyewear fogging. ${ }^{7,8}$

As for comparisons, the $3 \mathrm{M} 8833$ has a cushioned liner inside a sturdy shell shape with an external nose clip, which should be moulded to the clinician's nose, ${ }^{7}$ whereas the $3 \mathrm{M} 1873 \mathrm{~V}$ mask has a smooth lining found within three panels which are folded out to be worn; the panel covering the chin is adjustable ${ }^{8}$ and there is a mouldable nose fitting which is located internally. ${ }^{8}$

As dental professionals, we perform aerosol generating procedures (AGPs), such as using the high-speed handpiece; ${ }^{4}$ these produce airborne particles - FFP3 masks help to avoid their inhalation. ${ }^{4}$

The Health and Safety Executive (HSE) has indicated that the FFP3 masks have $\geq 99 \%$ ( $95 \mathrm{l} / \mathrm{min}$ ) filter efficiency and have a total inward leakage of $\leq 2 \%$; this includes a facial seal leak. ${ }^{5}$ To aid PPE selection, a local risk assessment is required. ${ }^{9}$

\section{Why do I need a face fit test and what are the two types of respiratory protective equipment fit tests?} Prior to wearing a FFP3 mask, you need to have passed the face fit test - if there is an inadequate seal, your protection can be undermined. ${ }^{6}$ The two types of respiratory protective equipment (RPE) fit tests are:

1. Qualitative: when wearing a mask and hood, a solution is sprayed; the candidate should not be able to taste the solution (sweet or bitter). ${ }^{5}$ This test can be used with half masks, not full-face versions ${ }^{10}$

2. Quantitative: a comparison between the particle proportions in and out of the mask. ${ }^{5}$ This test can be used with both half- and full-face varieties of the masks. ${ }^{10}$

There are different reasons for having a face fit test, including needing a repeat fit test (Fig. 3). ${ }^{6}$

The qualitative test and how it is performed

The test is carried out by one person. You should notice them adhere 
to social distancing, positioned away from you when delivering the instructions and when demonstrating how to put a mask on. Each person tends to have a 30-minute slot allocated to their test.

Prior to the fit test, a taste sensitivity screening is performed. You should be nil by mouth (including chewing gum) and should not smoke for at least 15 minutes before your taste sensitivity screening/fit test. ${ }^{11} \mathrm{~A}$ hood is placed over your head (Fig. 4) and you should have you mouth open slightly. The operator then squeezes the bulb of the nebuliser, ${ }^{11}$ producing an aerosol in the hood (Fig. 5); you must indicate if you can detect its taste ${ }^{11}$ (some are sweet, some bitter). If you are sensitive to the taste, you can then proceed to the fit test; if not, a different fit test is needed. The hood is removed and you should drink water to help eliminate the aerosol taste before your fit test. ${ }^{11}$

The fit test begins with a demonstration of how to put on a FFP3 mask by the tester. The candidate then puts their own mask on and moulds it to their face. It is useful to either use a mirror ${ }^{11}$ or have a colleague visually check you have the mask on correctly (for example, checking hair is not trapped in the seal of their mask).

As part of the fit test, a fit check is performed. Exhale and place your hand around, but not touching, the mask; you should not feel air escaping (for example, from under your chin). You may, however, feel air expel through the mask valve.

The hood is then placed over your head again. The aerosol is once again sprayed, this time while you perform various tasks (each for 60 seconds).$^{11}$ You should indicate to the tester if you can taste the aerosol at any point in the fit test.

The tasks are performed in this order:

1. Breathe normally (as you did in the taste sensitivity screening)

2. Breathe deeply

3. Move your head side to side (Fig. 6)

4. Move your head up and down (Fig. 7)

5. Read aloud - a text may be provided to you

6. Jogging/position yourself as you would if you were performing a dental procedure

7. Repeat step one.

If you do not taste the aerosol during your test, you have passed the test and the mask is deemed to provide an adequate fit for you. If you do taste the aerosol, you have failed the test and the mask is deemed an inadequate fit for you; ${ }^{11}$ you may be retested with a different type, size or model of a FFP3 mask. ${ }^{6}$

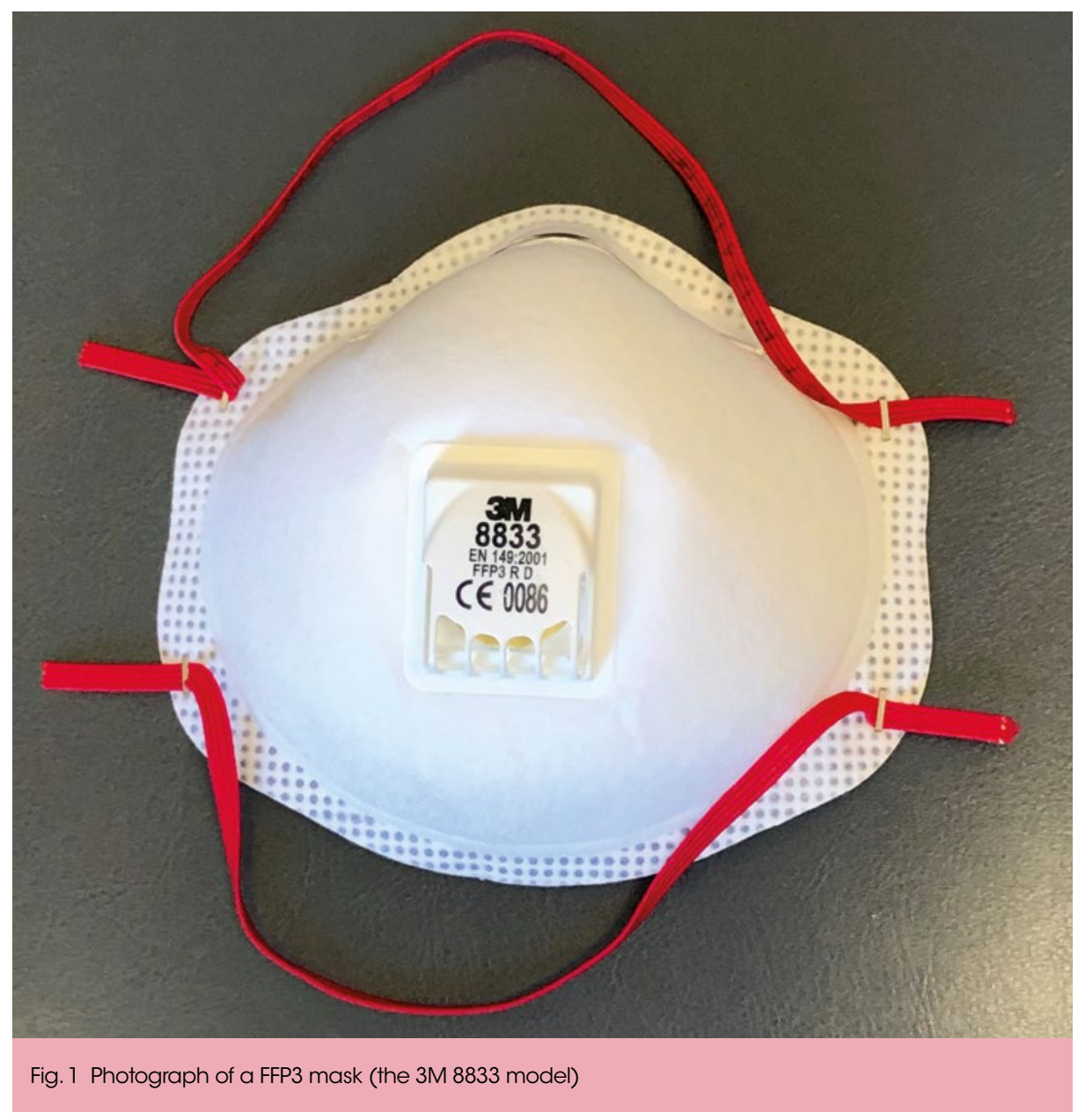

'If you do not taste the aerosol during' your test, you have passed the test and the mask is deemed to provide an adequate fit for you. If you do taste the aerosol, you have failed the test...

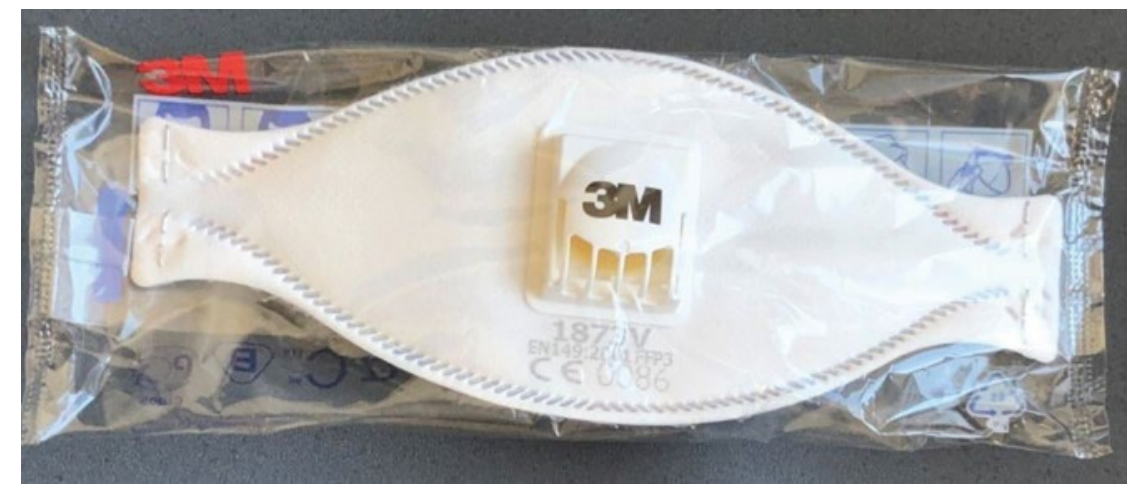

Fig. 2 Photograph of a FFP3 mask (the 3M 1873V model) 
Fig. 3 Graphic explaining four reasons to have a face fit test
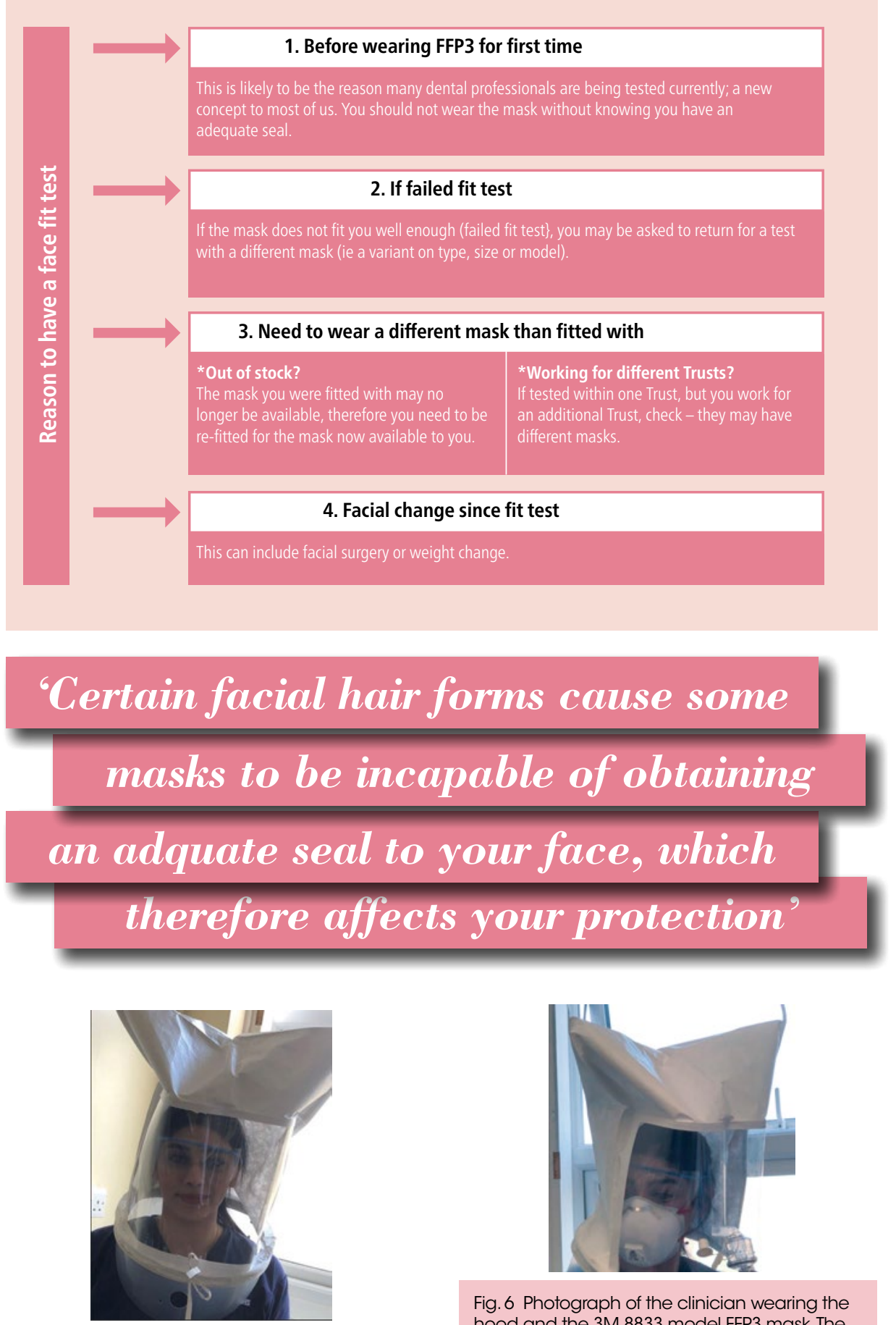

Fig. 4 Photograph of a clinician wearing the hood before the fit test

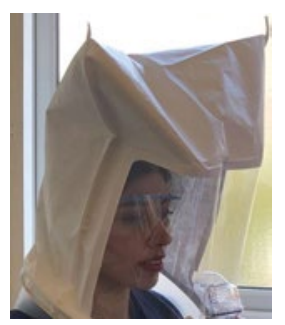

Fig. 5 Photograph of the clinician having their taste sensitivity screening. The testing solution is sprayed into the hood (see bottom right)

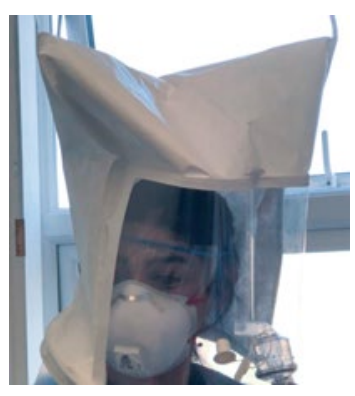

Fig. 6 Photograph of the clinician wearing the hood and the 3M 8833 model FFP3 mask. The solution is sprayed into the hood, while the clinician moves their head side to side

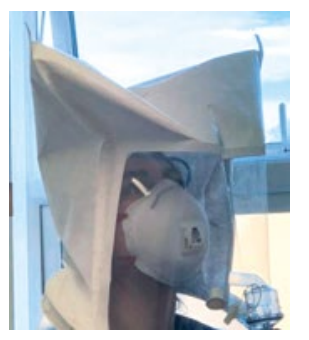

Fig. 7 Photograph of the clinician wearing the hood and the 3M 8833 model FFP3 mask. The solution is sprayed into the hood, while the clinician moves their head up and down
Fit testing documentation and indemnity considerations

As a fit test candidate, it would be beneficial to record the date and result (that is, pass or fail) of your fit test, ${ }^{10}$ in addition to taking a photograph of the mask you were tested with to act as an aide memoire.

In contrast, you may be adopting the role as a fit tester. For this, you must be competent ${ }^{10}$ and have undergone training, ${ }^{12}$ such as that offered by the accredited provider Fit2Fit ${ }^{10,13}$ recognised by HSE. For each candidate you fit test, documentation should be made, including their name, the test result, the type of mask tested with and the method used (qualitative or quantitative). ${ }^{10}$

Indemnity providers are providing different cover for those performing fit testing; ${ }^{12,14}$ check with your own indemnity provider to ascertain which cover you have for providing fit tests.

\section{Does facial hair affect the fit?}

Certain facial hair forms cause some masks to be incapable of obtaining an adequate seal to your face, which therefore affects your protection against the virus. ${ }^{15}$ The Centres for Disease Control and Prevention (CDC) have indicated which styles would not be compatible with the respirator: stubble, full beard and extended goatee. Those suggested as acceptable are a: soul patch, side whiskers and walrus moustache. ${ }^{16}$ Please note these lists are not exhaustive.

There are reasons some people cannot remove their beard (that is, on religious grounds); the HSE has indicated that there are alternative RPE. ${ }^{15}$

\section{Conclusion}

COVID-19 is changing the way in which dental professionals work. A FFP3 mask can be an important and essential part of our PPE. You should perform and pass a fit test before wearing a FFP3 mask. Moreover, it is important to know that every time you wear a FFP3 mask, you should perform a fit check; this should not substitute a fit test. ${ }^{5}$

\section{Acknowledgements}

The author would like to acknowledge Dr Saba Mirza (Dental Officer, Worcestershire Community Dental Service) for the photographs used in this publication.

\section{References}

1. World Health Organisation. Q\&A on coronaviruses (COVID-19). 2020.

Available online at https://www.who.int/ news-room/q-a-detail/q-a-coronaviruses (accessed April 2020).

2. The Centres for Disease Control and Prevention. Frequently Asked Questions. 


\section{'Indemnity provides are providing}

\section{different cover for those performing}

\section{fit testing; check with your own}

\section{indemnity provider to ascertain which}

\section{cover you have for providing fit tests.}

2020. Available online at https://www. cdc.gov/coronavirus/2019-ncov/faq.html (accessed April 2020).

3. NHS. Standard operating procedure: Transition to recovery - A phased transition for dental practices towards the resumption of the full range of dental provision. 2020. Available at https://www. england.nhs.uk/coronavirus/wp-content/ uploads/sites/52/2020/06/C0575-dentaltransition-to-recovery-SOP-4June.pdf (accessed June 2020).

4. Public Health England. Guidance: COVID-19 personal protective equipment (PPE). 2020. Available at https://www. gov.uk/government/publications/ wuhan-novel-coronavirus-infectionprevention-and-control/covid-19personal-protective-equipment-ppe (accessed April 2020).

5. Health and Safety Executive. Rapid Evidence Review. 2020. Available at https://www.hse.gov.uk/news/assets/docs/ face-mask-equivalence-aprons-gown-eyeprotection.pdf (accessed April 2020).

6. Health and Safety Executive. Fit testing face masks to avoid transmission: coronavirus (COVID19). 2020. Available at https://www.hse.gov.uk/news/ facemaskpperpecoronavirus.htm (accessed April 2020).

7. $3 \mathrm{M} .3 \mathrm{M}^{\mathrm{Ts}}$ Disposable Respirator, FFP3, Valved, 8833. Available online at https:// www.3m.co.uk/3M/en_GB/company$\mathrm{uk} / 3 \mathrm{~m}$-products/?N=5002385 $+8711017+3$ 290904880\&rt=rud (accessed June 2020).

8. 3M. 3M Aura Disposable Healthcare Respirator, FFP3, Valved, 1873V+. Available online at https:// www.3m.co.uk/3M/en_GB/ company-uk/3m-products/ /3MAura-Disposable-Healthcare-RespiratorFFP3-Valved-1873V-/?N=5002385+3292 799385\&preselect $=3293786499 \& \mathrm{rt}=\mathrm{rud}$ (accessed June 2020).
9. Health and Safety Executive. Research: review of personal protective equipment provided in health care settings to manage risk during the coronavirus outbreak. 2020. Available at https://www.hse.gov.uk/ coronavirus/ppe-face-masks/face-maskequivalence-aprons-gowns-eye-protection. htm (accessed April 2020).

10. Health and Safety Executive. Guidance on respiratory protective equipment (RPE) fit testing. 2019. Available at https://www.hse. gov.uk/pubns/indg479.pdf (accessed June 2020).

11. Moldex-Metric. BITREX: Qualitative Fit Test Instructions. Available at https://www. moldex.com/pdf/misc/bitrex_fit_test_kit. pdf (accessed April 2020).

12.DDU. COVID-19 resources: Supporting you when you need it. 2020. Available online at https://www.theddu.com/ coronavirus (accessed June 2020).

13. BSIF. Fit2Fit Accreditation. Available online at https://www.fit2fit.org/ (accessed June 2020).

14.Dental Protection. Fit testing of masks - Dental Protection position statement. 2020. Available at https:// www.dentalprotection.org/uk/articles/ fit-testing-of-masks-dental-protectionposition-statement (accessed June 2020).

15. Health and Safety Executive. Fit testing basics. Available at https://www.hse.gov. $\mathrm{uk} /$ respiratory-protective-equipment/fittesting-basics.htm (accessed April 2020).

16. Centres for Disease Control and Prevention. To Beard or not to Beard? That's a good Question! 2017. Available at https://blogs.cdc.gov/niosh-scienceblog/2017/11/02/noshave/ (accessed April 2020).

This article was originally published in the $\mathrm{BDJ}$ on 24 July 2020, Volume 229 issue 2, pages 112-114.

https://doi.org/10.1038/s41407-020-0404-z

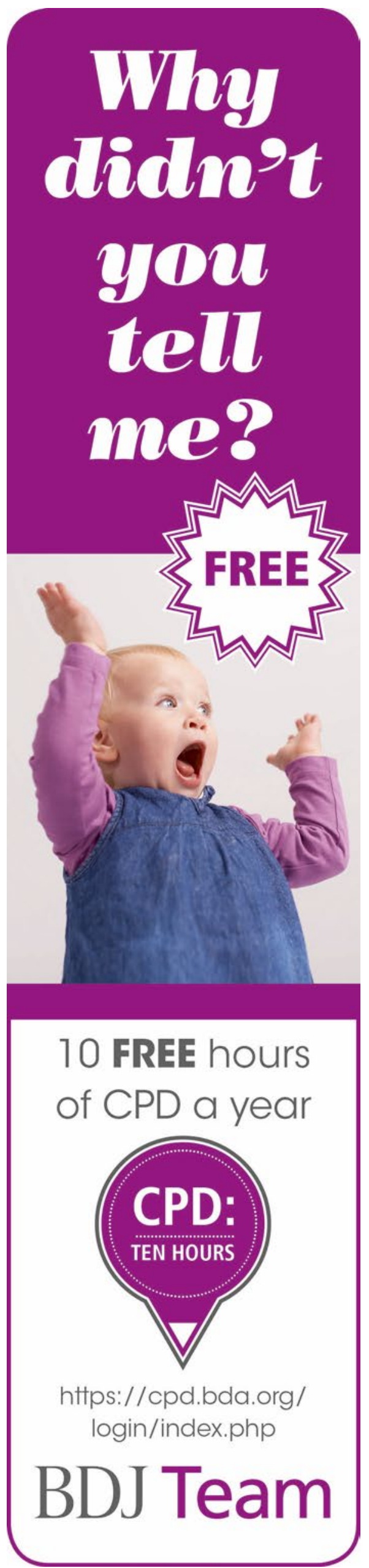

